\title{
Mapping the world: cartographic and geographic visualization by the United Nations Geospatial Information Section (formerly Cartographic Section)
}

\author{
Ayako Kagawa, Guillaume Le Sourd ${ }^{\mathrm{a}, \mathrm{b}}$ \\ ${ }^{a}$ Authors are officers at the Geospatial Information Section (formerly Cartographic Section), Department of Field Support, United \\ Nations, New York, United States of America; kagawa@un.org, lesourd@un.org,www.un.org/gis \\ ${ }^{b}$ The views expressed are those of the author(s) and do not necessarily reflect those of the United Nations. (ST/AI/189/Add.6/Rev.4)
}

\begin{abstract}
United Nations Secretariat activities, mapping began in 1946, and by 1951, the need for maps increased and an office with a team of cartographers was established. Since then, with the development of technologies including internet, remote sensing, unmanned aerial systems, relationship database management and information systems, geospatial information provides an ever-increasing variation of support to the work of the Organization for planning of operations, decision-making and monitoring of crises. However, the need for maps has remained intact. This presentation aims to highlight some of the cartographic representation styles over the decades by reviewing the evolution of selected maps by the office, and noting the changing cognitive and semiotic aspects of cartographic and geographic visualization required by the United Nations. Through presentation and analysis of these maps, the changing dynamics of the Organization in information management can be reflected, with a reminder of the continuing and expanding deconstructionist role of a cartographer, now geospatial information management experts.
\end{abstract}

Keywords: Maps, geospatial information, United Nations

\section{Introduction}

. The United Nations has been producing and using maps since 1945 to support the needs of the United Nations Secretariat. Over the past seven decades, the need for maps has continued but as information and communication technologies have developed, the area of geospatial information support has expanded in the office by applying geo- graphic information systems, remote sensing and unmanned aerial systems to provide evidentiary support and solutions for the decision-makers. Whilst the medium is shifting from providing static maps to dynamic multi-scale, multi-dimensional spatialtemporal online maps, the need for maps has remained intact. Whilst multiple offices have emerged to provide some form of mapping, this presentation will be highlighting the work by the United Nations Geospatial Information Section (formerly Cartographic Section).

This presentation aims to highlight some of the cartographic representation styles by the United Nations cartographers over the decades by reviewing the selected maps under frameworks of map communication model (Board, 1967), cartographic technical framework of visual variables (Bertin, 1967) and applying the cartographic discourse framework of maps as social constructs (Crampton, 2001; Harley, 1989).

By placing these maps in these framework contexts, we argue that whilst these maps are produced with technical rigour reflecting the techniques of the time, consistently over the decades, the map makers have been taking the de- constructionist approach of leaving more messages in the space not filled in. As technology continues to change, the role of the cartographer, now geospatial information management experts will continue to expand as custodians of knowledge and communication.

\section{History of map making in the United Nations Geospatial Information Section (formerly Cartographic Section)}

The United Nations has been producing and using maps since 1945 to support the needs of the United Nations Secretariat and the countries who are Member States. Initially, there was one cartographer who was recruited in the Bureau of Documents of the Conference and General Services in 1946 but by 1951, the need for maps increased and the Cartographic Unit was established in the Department of Conference Services with a team of three cartographers. The office is now known as the Geospatial Information Section (formerly Cartographic Section) in the Department of Field Support, with a team of eight geospatial information management experts whose backgrounds range from cartography, engineering, geography, Geographic Information Services (GIS), information technology, remote sensing, and surveying ${ }^{1}$.

It is interesting to note the Section has moved various Divisions and Offices over the past seven decades starting from the Division of Social Welfare, Department of Social Affairs, Department of Conference Services, Department of Public Information, Department of Peacekeeping Operations, and today, in the Department of Field Support. This mobility reflects the different power dynamics of information transferring from one office to another, depending on the organizational emphasis and agenda of those times. 
Today, the Section continues the tradition and practice of providing geographic support to the United Nations Secretariat including (1) production of profile and deployment maps to be included in the official reports of the United Nations, (2) map clearance and guidance to United Nations Secretariat colleagues to ensure maps produced have one single cartographic practice, (3) provision of map publication permission grants on behalf of the United Nations Publications Board, (4) customized map production for the United Nations Security Council, (5) programme management of GIS in field missions in peace operations, (6) technical assistance to Member States on international boundary issues, and (7) serving as Co-Secretariat with the United Nations Statistics Division (UNSD) to the United Nations Committee of Experts on Global Geospatial Information Management (UN-GGIM) (United Nations, 1997, 2010, 2011, 2015).

Over the past seven decades, the Section has produced between 8,000 and 10,000 maps following the principles of sovereignty and common cartographic practice. In order to ensure that the United Nations produces maps in a consistent manner in its official publications, the Section is also responsible for providing advice and guidance on maps produced by other offices in the Organization (United Nations, 1997), but also extends to the larger United Nations family.

The majority of maps produced by the Section can be categorised as general profile and deployment maps, which are small scale maps in paper size format included in the official reports. However, the Section also produces small scale thematic maps for different clients across the Secretariat, and large scale planning maps for the offices dealing with peacekeeping and peace-building components for internal dissemination purposes. The data and information sources for mapping these internal products range tremendously but in the earlier days, it was dependent on the in- formation provided by the requesting clients and increasingly, open source information is also included as reference information by clients which requires rigorous validation processes.

Maps by the Section have been produced manually using the traditional scribing techniques until 1989 when the first digital map was produced using Apple Macintosh and later transmitted to a Windows operating system environment. During the 1990s, digital map production in the Section primarily used graphics software but with the transition to a Windows operating environment, GIS software was used to prepare datasets and finalise in the graphics environment. As of the 2010s, the Section has increasingly transitioned to preparation of maps in to a GIS environment, where the collection and management of data is managed through an database-driven enterprise sys- tem.

Readership of the official reports of the United Nations is diverse, ranging from the diplomatic community of the United Nations membership to students working on their academic theses. The profile maps are attached to official reports such as the General Assembly and SecretaryGeneral's reports to provide readers a broad geographical understanding of the landscape of where their issues are at hand, and these issues could range from the political pro- cess to the economic and social development situation on the ground. Deployment maps are primarily attached to Security Council and Secretary-General's reports, which provide the latest situation of the peacekeeping operations, where the map will illustrate the strategic military deployment presence of United Nations peacekeepers through Member State troop and police contributions.

Whilst these profile maps and deployment maps have been one of the longest standing products by the Section, it is worthwhile noting that the requesting office for revisions of these maps has changed over the years, reflecting the changing organizational structure in the practice and relationship of power-knowledge of map making. Noting that the United Nations is an international political organization set out by Member States, the rules of cartography encompass both the wellknown rules of technical production of maps and the lesser known rules for the cultural production of maps (Crampton, 2001:698). It is from this approach, that in order to critically demonstrate the evolution of the cartographic representation styles of the Section, it is essential to place these maps and map makers in a cartographic map communication model framework.

\section{Setting the map communication model framework to the United Nations setting}

The cartographic discipline has been shifting its paradigm over the past seven decades, all the while the cartographers of the United Nations have been producing maps. Cartographers such as Robinson were influential in creating the foundation of cartographic discipline in the modern age, to "produce a single, optimal (best) map, which presents information clearly, and which is based on known factors of map use" (Crampton, 2001: 694). The use of carto- graphic technical tools of visual variables (Bertin, 1963) is essential but may have overlooked the importance of cartographic discourse of maps as social constructs (Crampton, 2001; Harley, 1989). In this section, we argue that both the technical tools and the cartographic discourse needed to co-exist in the preparation and dissemination of maps, and hence, the framework of the map communication model (Board, 1967) is important as an overall encompassing framework.

The map communication model proposed by Board (1967) is in some ways epitomized in the maps by the Section, as the production of maps has involved iterative communication processes between the map reader and user who are the clients who provide the view of the world from an organizational and mandate perspective, whilst the cartographer provides the spatially precise, value-free representation, focusing on design practices (Crampton, 2001).

Whilst American and British cartographers contemplated the communication aspects of cartography, French cartographers focused on techniques of improving their 
discourse. The work and establishment of the guidelines of "visual variables" by Bertin (1967) has had tremendous impact to cartographic visualization till this day, and the products by the Section are no exception. In the context of profile and deployment maps by the Section, due to the scope of the products (small scale and paper size) and limitations of the technology at the time, amongst the six visual variables of position, size, shape, volume, value, colour, orientation and texture, the variables effectively used are of form, size and value. In the following section, some empirical demonstrations will be made of this.

Though agreeing to the deconstructionist approach in the role of maps by Harley where "a map is a silent arbiter of power" (Harley, 1989:13), some critics point to the lack of empirical work by the author, noting to the possibility that his understanding of the role of a map is limited to a universal function of the individual (Wood, 1993) and hence limiting. In the subsequent section, the authors argue that it is not only the map but the map maker who provides the discourse function, by looking at where the Section has been positioned from an organizational structure, as an instrument of how the information may have been flowing to the office.

\section{Applying the map communication model framework on the maps by the United Nations Geospatial Information Section}

This section will focus on how the concepts of the map communication model, visual variables, and deconstruction of the map can be applied to some of the selected maps produced by the Section over the past decades. The se- lection of the maps may not be a balanced representation due to technical challenges in identifying all the original maps held by the Section, especially in the early days of the office.

According to the Section's internal logbook of map production, the first map of the United Nations is a world map of Drainage Basins, Aridity and Irrigation in July 1946. During its first year, the Section was also responsible in preparing the United Nations Emblem, in December 1946, which demonstrates the office's role in producing infographics as it was under the Printing Division of the Bureau of Documents of Conference and General Services, an office responsible for meetings held in the United Nations ${ }^{2}$. Starting with United Nations logo map, geopolitical realities were already at play as the prototype map was "projection of the world used intended to have "all the countries of the world [...] spun around this concentric circle, but "limited $[\ldots]$ in the Southern sector to a parallel that cut off Argentina because Argentina was not to be a member of the United Nations" (Heller, 2009). Subsequent versions were

2 The original version was designed by Oliver Lincoln Lundquist working for the United States Office of Strategic Services in 1945 following the request for a United Nations logo during the San Francisco Conference whilst the United Nations Charter was being drafted. rectified to include the southern sector and Argentina. The General Assembly adopted the United Nations Emblem following Resolution 92 on 7 December 1946 (United Nations, 1946).

From a geopolitical perspective, one of the first regions in which the United Nations was heavily engaged was the Middle East, as one of its central missions is the maintenance of international peace and security. Whilst the United Nations Truce Supervision Organisation (UNTSO) was established in May 1948, making it the oldest peacekeeping mission, during the first three decades, maps in the early phases focused on thematic maps to demonstrate the socio- economic environment of the region (Palestine: Distribution of Population, Map No. 93, November 1947; Palestine: Land Ownership, Map No. 94, November 1947) or based on the agreed Armistice Agreement map $^{3}$, and therefore the first UNTSO deployment map only appears in July 1997. However, reviewing the maps such as the profile of Israel (Israel, Map No. 3584 Rev. 2, January 2004), it also reflects the long engagement of the issues by the United Nations. Visual variables such as shape and texture are used to maximum effect to communicate the delicate geopolitical realities of the region. Through the use of different type of lines (international boundary line, Armistice Agreement line, former Palestine Mandate boundary, occupied Palestinian territory lines of West Bank and Gaza) and shape (district centre symbol for Tel Aviv-Yaffo and Jerusalem), the cartographer subtly illustrates the complicated realities, legacies and practices. Furthermore, the sovereign state such as Israel is annotated using serif fonts whilst the occupied Palestinian territories of West Bank and Gaza use a sans serif font, following common carto- graphic practice of the Section. It is in these applications of visual variables that a cartographic discourse exists in the maps by the Section.

During the 1950s and through the 1970s, trust territories in the regions of Africa and Asia were administered through the United Nations Trusteeship Council. One of the earliest trust territory profile maps was for Togoland and Cameroons, which were territories under both the United Kingdom and French administrations (Trust Territories, Map No. 335, September 1951). Taking the example of Trust Territory of Tanganika (Trust Territory of Tan- ganika: Map No. 341, September 1951), the area of interest to this day is kept in the regional profile map of East African Community (Map No. 4248 Rev.1, June 2012). The practice of keeping consistency in terms of visual variables such as size and orientation of the maps, but also the geographic information such as country names, first administrative order names, national capital names, hydrography, and infrastructure such as roads and railways, al- lows the map user to have a consistent branding image of the products by the Organization.

The Armistice Agreement Map of 1949 is based on the map originally produced by the Survey of Palestine in 1946, and reproduced by the United Nations. 
The earliest deployment map series that has come into production consistently using the same cartographic style is that of the United Nations Disengagement Observer Force (UNDOF) which was established in May 1974 but its first deployment map attached to an official report is one of November 1976 (UNDOF, Map No. 2916 November 1976$)^{4}$. In the initial deployment map, three visual variables are effectively used to illustrate the deployment status. These are shape (circle for position and triangle for observer post - these are still used to this day), texture (dashed line for patrol routes) and colour (blue for the Area of Separation). Today, these visual variables of shape and colour are maintained but with the combination of these, position and observer post are now coloured blue for emphasis on presence of the United Nations. Following the cartographic practice of the maps in the Section, the sovereign states are annotated using serif fonts whilst Golan, the area of contention, uses a sans serif font. The reference frame is unique as it includes both latitude and longitude, and a reference frame based on the Palestinian Belt Grid. Today, both these coordinates are no longer used on the ground but have been kept deliberately. Whilst the geographical area of responsibility of UNDOF has remained the same over the past four decades, due to the changing political landscape, its headquarters has changed at times, but for messaging purposes to the international community, the area of interest and the location of headquarters on this map has not changed to-date. The visual variable consistency since the establishment of the mission illustrates the importance of the cartographic discourse role.

The importance of the role of deployment maps can also be demonstrated from the fact that during the 1970s and 1980s, the request for an update of these maps came directly from the mission's Force Commander to the Secretary- General and on to the Section. In the 1990s, this communication was delegated from the mission's civilian head to the Under-Secretary-General of the newly established Department of Peacekeeping ., and

\footnotetext{
${ }^{4}$ The map title and the legend are prepared in the five official United Nations languages of English, Chinese, French, Russian and Spanish. The fact that the Arabic map title and map legend starts appearing in May 1983 (UNDOF, Map No. 2916 Rev.13 May 1983) and thereafter appear consistently, provides us the assumption the technical challenges in including different languages existed at the time. The use of the six official United Nations languages has since been omitted, but this has been due to the technical challenge of not being able to transfer different fonts from one operating system to another when the mapping interface shifted from Apple Macintosh to Windows frame in 2008. There has also been information from predecessors that certain fonts were not possible to create in a manual environment.

All maps prepared by the United Nations include a standard disclaimer text of "The boundaries and names shown and the designations used on this map do not imply official endorsement or acceptance by the United Nations". In the case of profile maps of Sudan and South Sudan, additional special disclaimer texts are also included: "Final boundary between the Republic of Sudan and the
}

presuming the extensive expansion of the peacekeeping mission files in the 1990s, this communication flow was delegated further down to the operational level. Today, revision requests for deployment maps come from the Office of Military Affairs of the Department of Peacekeeping Operations to the Section directly, reflecting the changes in the level of discourse with regards to information, and hence the democratization of information and power within the Organization.

The Democratic Republic of the Congo is another example of where the United Nations has continuously been trying to provide assistance in ensuring nation state building. Since the establishment of the United Nations, the country has changed its name from Belgian Congo, Congo (Leopoldville), Zaire to Republic of Congo (Republic of Congo, Map No. 1319 series), and the Democratic Republic of the Congo (DRC; Map No. 4007 series). The deployment map of July 1960 (The Republic of the Congo: Deployment of units of the United Nations Force as at 31 July 1960, Map No. 1272, February 1961) may have been one of the last maps used by SecretaryGeneral Dag Hammarskjold, who was killed in a tragic plane crash in September 1961 while en route to negotiate a cease-fire in that country. The internal office production log again illustrates that the map was requested directly from the Secretary-General's office. Today, the United Nations Mission in the Democratic Republic of Congo (MONUC, Map No. 4121 series), established in 1999 following the peace process, has transformed into the United Nations Organisation Stabilization Mission in the Democratic Republic of the Congo (MONUSCO, Map No. 4412 series) since 2010. When reviewing the presence of United Nations peacekeepers in the 1960s, troop contributing countries have been from Member States of the regions of Africa (Ethiopia, Guinea, Liberia, Ghana, Morocco and Tunisia) and Europe (Ireland and Sweden). Today, the troop contributing countries include regions of Africa (Benin, Egypt, Ghana, Morocco, Senegal, South Africa, Tanzania), the Americas (Guatemala, Uruguay), Asia (Bangladesh, China, Nepal, India, Indonesia, Pakistan) and Europe (Ukraine), reflecting the increased diversity and presence of Member States on the ground.

The United Nations Mission in South Sudan (UNMISS) is a peacekeeping mission which was established with the independent Republic of South Sudan coming into existence in July 2011. The United Nations had been supporting the efforts to the build-up to the Comprehensive Peace Agreement between the government of Sudan and the Sudan People's Liberation Movement in 2005 at its implementation until the establishment of a newly independent state under United Nations Mission in Sudan (UNMIS) mandate. One of the cartographic challenges in preparing the profile maps of Sudan and South Sudan was the lack of information with regards to the determination of the international boundary.

Republic of South Sudan has not yet been determined. Final status of the Abyei area is not yet determined. 
Unfortunately, the international boundary line to-date is undetermined as the Parties have yet to agree with the final boundary, and at the same time, another disputed territory of Abyei area has come into existance. Due to operational requirements, the Section does have profile maps of these areas and uses visual variables of value and texture to communicate the position of the Organization. The international boundary between Sudan and South Sudan does not use the standard international boundary line but one which clearly is categorized as an undetermined boundary, whilst Abyei area is colourised and depicted in a manner that insinuates that the area is neither Sudan nor South Sudan. Additionally, the maps include special disclaimer texts pertaining to these undetermined boundaries and Abyei area, following the consultation by policy makers and map makers ${ }^{6}$. The sustained emphasis of certain geographical areas not pertaining to one or the other provides a strong discourse to the map user, that these maps need to be used with caution.

The World in 1945 (Map No. 4135, December 1999; Rev.3, May 2010) and The World Today (Map No. 4136, December 1999; Rev.11, August 2013) are two thematic maps of the Section which summarise the state of the world using the visual variable of colour effectively. The visual variable of colour is striking, especially those which were categorized as Non-Member States and other dependent territories. Whilst the cartographic visualization of these maps may bring unwanted attention on another discourse which took place in the past of what map projection would be most suitable for this Organization (United Nations, 1989) as the maps are highly generalized and simplified, these maps demonstrate the cartographic discourse of one of the principal foundations of the Organization, the prin- ciple of sovereignty. It is clear that when the United Nations started out in 1945, the status of these Member States and territories was very different to what it is today, as the seven classes of types diminishes to four classes, revealing the changing geopolitical dynamics over the past seven decades, and potentially changing as the world order continues to change.

\section{Tomorrow's map making in the United Nations}

With the development of technologies including internet, remote sensing, unmanned aerial systems, relationship database management and information systems, geospatial information provides an ever-increasing opportunity to support the work of the Organization for

${ }^{6}$ All maps prepared by the United Nations include a standard disclaimer text of "The boundaries and names shown and the designations used on this map do not imply official endorsement or acceptance by the United Nations". In the case of profile maps of Sudan and South Sudan, additional special disclaimer texts are also included: "Final boundary between the Republic of Sudan and the Republic of South Sudan has not yet been determined. Final status of the Abyei area is not yet determined. planning of operations, decision-making and monitoring of crisis. Whilst the medium is shifting from providing static maps to dynamic multi-scale and multi-dimensional spatial-temporal online maps, the need for maps in providing a common operational picture for decisionmakers has remained intact. Over the decades, multiple offices have emerged to provide some form of mapping or geospatial information in the Organization but to-date, the Section, now under the Information and Communications Technology Division of the Department of Field Support, is continuously transitioning its role as geospatial information management expert office. The fact that the divisional mission is to deliver technologybased solutions to the United Nations, and the fact that geospatial information technology is continuously expanding and improving, the deconstructions role of geo- spatial information management experts does not seem to diminish in the coming future.

Regardless of the continuous evolvement of mediums and technologies, the shifting geopolitical realities of the world, map makers of the Section believes that our role is in the assurance in providing a constant, through our maps, to be the silent arbiter of power as custodians of spatial knowledge and communication.

\section{References}

Bertin, J. (1967). Sémiologie graphique: Les diagrammes, les résaux, les cartes. Paris: Gauthier-Villars.

Board, C. (1967). Maps as models, In R. J. Chorley, and P. Haggett (eds), Models in Geography. London: Methuen, 671-725 Board, C. (1981). Cartographic Communication, Cartographica 18 (2), 42-78.

Crampton, J.W., (2001). Map as Social Constructions: Power, Communication and Visualization, Progress in Human Geography, (pp.

235-520. SAGE Publication.

Harley, J.B., (1989). Deconstructing the Map, Cartographica, 26, (2), 1-20.

Heller, S. (2009) Oliver Lincoln Lundquist, Designer, Is Dead at 92. New York Times. 3 January 2009 http:/www.nytimes.com/2009/01/04/world/04lundquist. html Accessed 1 March 2017.

United Nations (1946). Official Seal and Emblem of the United Nations, A/RES/92 http://www.un.org/ga/search/view_doc.asp?symbol=A/ RES/92(I) Accessed 27 February 2017.

United Nations (1947-2017). Map Logbook (internal logbook), United Nations Geospatial Information Section (formerly Cartographic Section).

United Nations (1979). Administrative Instruction Guideline on control of documents: Use of the United Nations Emblem on Documents and Publications http://www.un.org/ga/search/view_doc.asp?symbol=ST/ AI/189/Add.21 Accessed 27 February 2017.

United Nations (1996). Guideline on control of documents: Attribution of authorship in United Nations documents, publication and oth- er official papers, ST/AI/189/Add.6/Rev5. 
United Nations (1997). Guideline on control of documents: Publication of Maps, ST/AI/189/Add.25/1. http://www.un.org/Depts/Cartographic/ST-AI-189-

Add_25-Rev_1.htm Accessed 20 February 2017.

United Nations (2000) Secretariat News January February 2000. Department Watch: Mapping Technology.

United Nations (2010) Secretary-General's bulletin: Organization of the Department of Field Support, ST/SGB/2010/2

http://www.un.org/ga/search/view_doc.asp?symbol=\% $\% 2$ 0ST/SGB/2010/2 Accessed 1 March 2017.

United Nations (2011) 2011/24 Committee of Experts on Global Geospatial Information Management, http://www.un.org/en/ecosoc/docs/2011/res\%202011.24 .pdf Accessed 1 March 2017.

United Nations (2015) Map use at the United Nations, International Cartographic Association. International Map Year 2015-2016. http://mapyear.org/files/wom/10_IMY_WoM_en.pdf Accessed 20 February 2017.

United Nations (2017) Factsheet: United Nations Emblem and Flag, http://ask.un.org/loader.php? fid=2800\&type $=1 \&$ key $=4 \mathrm{e}$ 33d55b2d943764e5085a395d74ccd6 Accessed 27 February 2017.

United Nations (2017). List of Peacekeeping Operations: 1947 - 2013 http://www.un.org/en/peacekeeping/documents/operatio nslist.pdf Accessed 20 February 2017.

Wood, D. (1993). The fine line between mapping and mapmaking, Cartographica, 30 (4), 50-60.

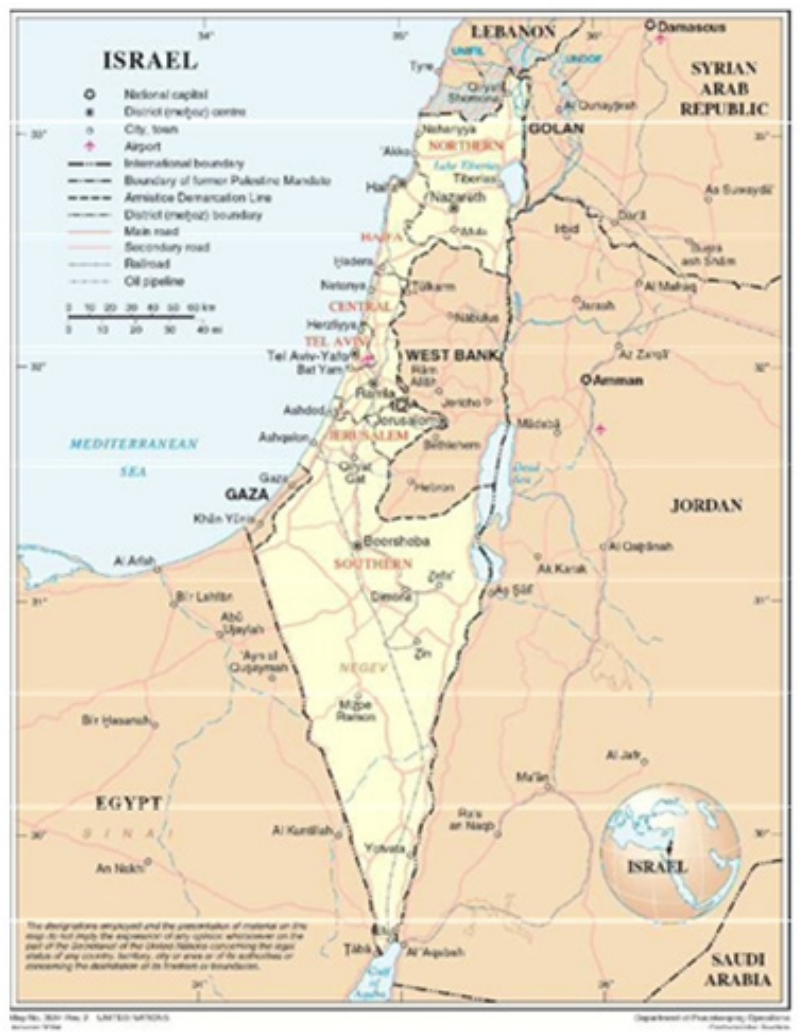

Map 1: Israel, Map No. 3854 Rev.2 January 2004 (http://www.un.org/Depts/Cartographic/map/profile/israel.pdf )

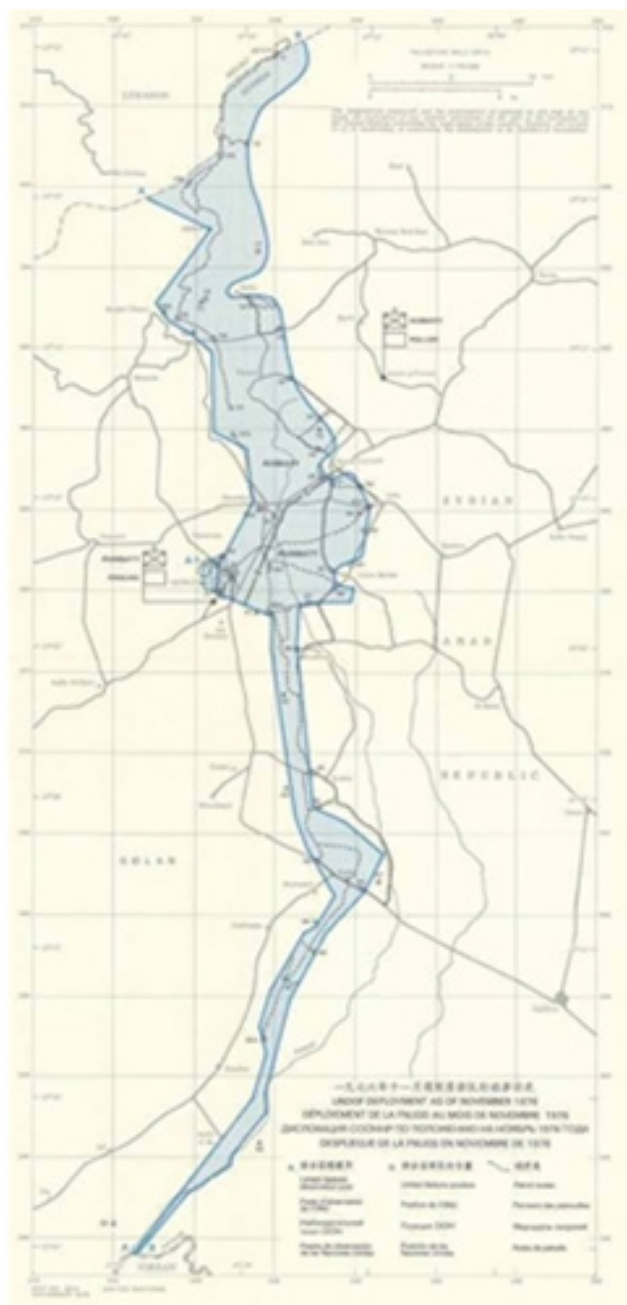

Map 2: UNDOF, Map No. 2916 November 1976 


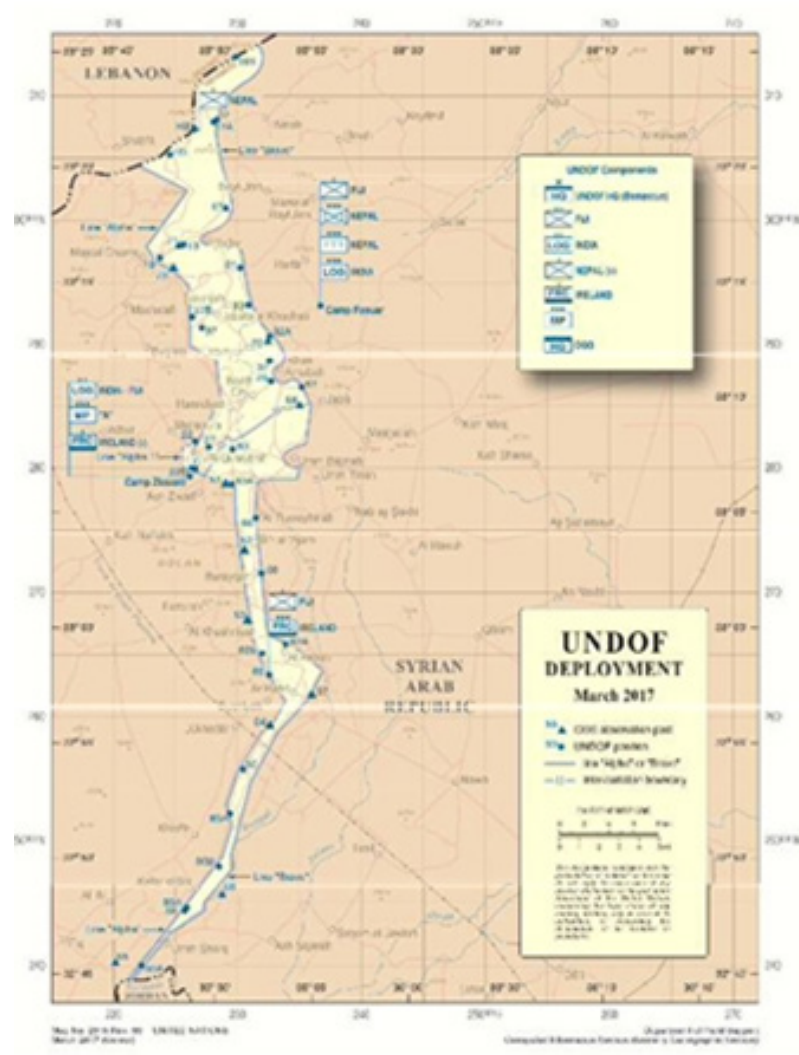

Map 3: UNDOF, Map No. 2916 Rev. 99 March 2017 (http://www.un.org/Depts/Cartographic/map/dpko/undof.pdf)

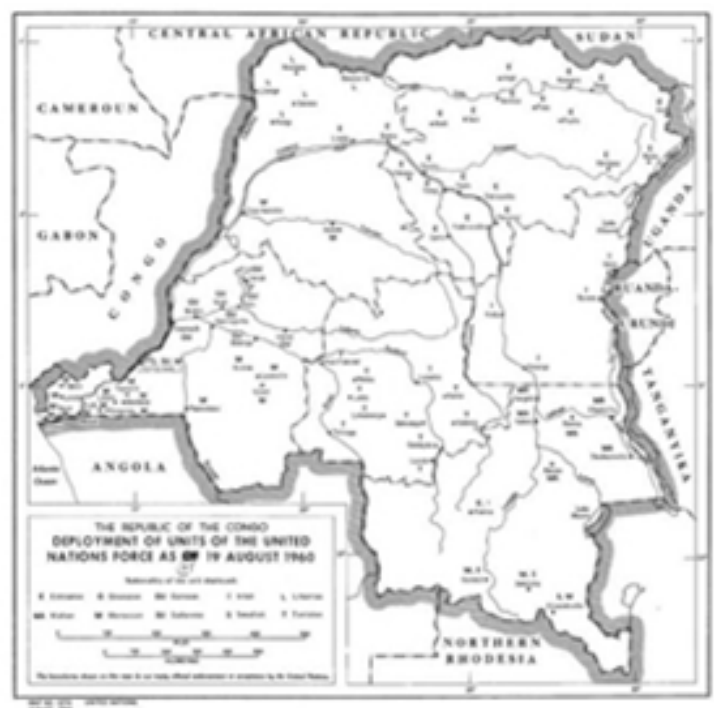

Map 4: The Republic of the Congo: Deployment of units of the United Nations Force as at 31 July 1960, Map No. 1272, February 1961

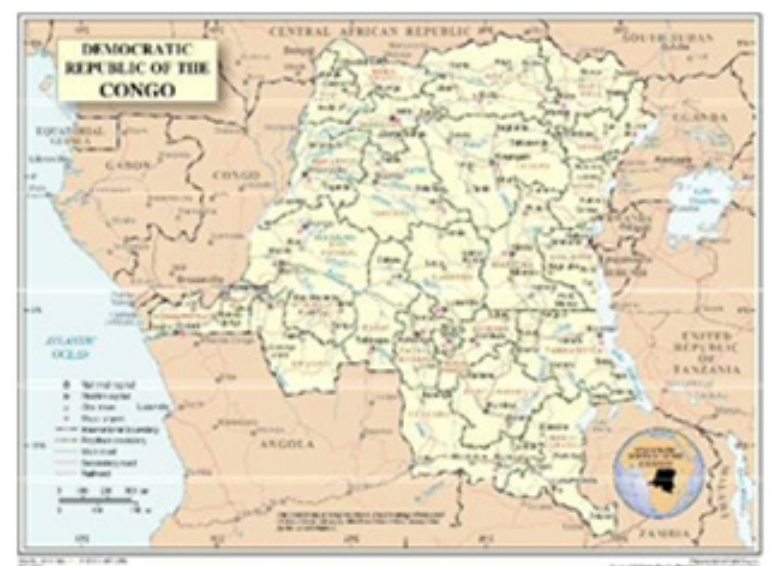

Map 5: Democratic Republic of the Congo, Map No. 4007 Rev. 11 May (http://www.un.org/Depts/Cartographic/map/profile/drcongo.pd f)

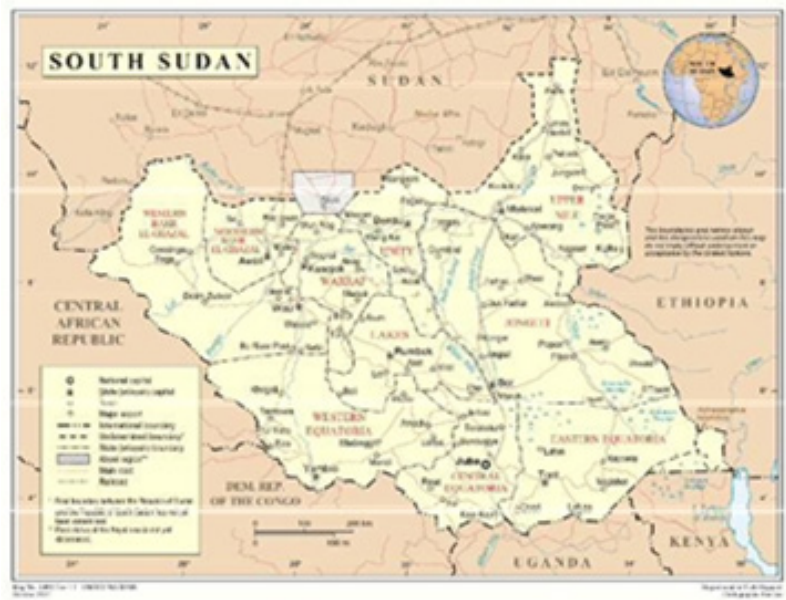

Map 6: South Sudan, Map No. 4450 Rev.1.1, October 2011 (http://www.un.org/Depts/Cartographic/map/profile/southsudan. pdf) 